\title{
In Focus
Spotlight on the September 30 Issue
}

\author{
Robert A. Gross, MD, PhD, FAAN \\ Editor-in-Chief, Neurology ${ }^{\circledR}$
}

Stroke subtype, vascular risk factors, and total MRI brain small-vessel disease burden OPEN Pt

The additive total small-vessel disease (SVD) burden score is associated with lacunar stroke and represents the effect. This result suggests that smoking and hypertension are preventable risk factors and that this burden score should be used in research and clinical practice to capture the overall consequences of SVD.

See p. 1228

From editorialists Jickling \& Chen: "As the scale is refined, the hope is that a comprehensive evaluation of cerebral SVD will improve our understanding and treatment of SVD, and ultimately improve brain health."

See p. 1224

Classification algorithms using multiple MRI features in mild traumatic brain injury

Multifeature analysis was performed using MRI metrics obtained at 3T, focusing on 5 regional gray and white matter volumes including the anterior cingulum and left frontal and temporal poles. The analysis of 24 patients with mild traumatic brain injury and 26 controls yielded accuracy of $80 \%$ using the full feature set and $86 \%$ using minimalredundancy maximal-relevance selected features.

See p. 1235; Editorial, p. 1226

Midlife migraine and late-life parkinsonism: AGES-Reykjavik Study

In this study, patients with midlife migraine, particularly migraine with aura, reported late-life parkinsonian symptoms, Parkinson disease, and family history of Parkinson disease. These associations were not related to comorbid cardiovascular disease, suggesting the possibility of a shared genetic or environmental pathway linking migraine with parkinsonism.

See p. 1246

Predictors of dementia in Parkinson disease: A prospective cohort study

Dementia is a devastating yet difficult-to-predict complication of Parkinson disease (PD). This 4-year study identified an array of dementia predictors based on easily obtainable bedside data. In addition to mild cognitive impairment, the predictors of dementia in PD were REM sleep behavior disorder, cardiovascular dysfunction, gait dysfunction, and poor color vision.

of

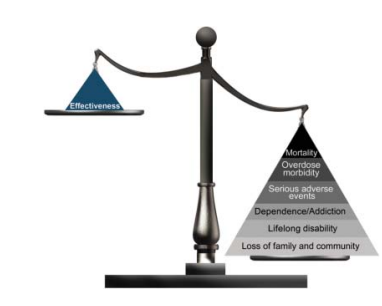

Oral fluoroquinolone use and risk of peripheral neuropathy: A pharmacoepidemiologic study

This study underscores the risk of peripheral neuropathy with oral fluoroquinolone antibiotics. Older men who used oral fluoroquinolones had an increased risk of developing peripheral neuropathy compared with nonusers. Clinicians should weigh the benefits against the risk of adverse events when prescribing these drugs.

See p. 1261

Sensitivity and specificity of diagnostic ultrasound in the diagnosis of phrenic neuropathy

Eighty-two patients presenting with unexplained dyspnea underwent ultrasound of the diaphragm. Based on thickness of the diaphragm and contractility, ultrasound was $93 \%$ sensitive and $100 \%$ specific in diagnosing neuromuscular dysfunction of the diaphragm. Ultrasound is a readily available bedside tool that has high sensitivity and specificity in diagnosing phrenic neuropathy.

See p. 1264

ABO blood type, factor VIII, and incident cognitive impairment in the REGARDS cohort

$A B O$ blood group was measured by genotyping in a nested casecontrol sample of 495 patients with cognitive impairment and 587 controls. Blood group AB and higher factor VIII (FVIII) were associated with increased incidence of cognitive impairment, whereas blood group $A B$ with incident cognitive impairment was not mediated by FVIII levels.

See p. 1271

\section{SPECIAL ARTICLE}

Opioids for chronic noncancer pain: A position paper of the American Academy of Neurology

The opioid overdose epidemic is one of the worst man-made problems in the history of medicine, with a "lost generation" whose lives have not been made better by chronic use of opioids. The evidence for long-term substantial benefit of opioids for chronic pain is low but evidence for substantial harm is high.

See p. 1277

NB: "Challenges to ethics and professionalism facing the contemporary neurologist," see p. 1285. To check out other Contemporary Issues: Horizons submissions, point your browser to Neurology.org.

Podcasts can be accessed at Neurology.org 


\title{
Neurology
}

\author{
Spotlight on the September 30 Issue \\ Robert A. Gross \\ Neurology 2014;83;1223 \\ DOI 10.1212/WNL.0000000000000852
}

This information is current as of September 29, 2014

\section{Updated Information \&}

Services

Permissions \& Licensing

Reprints including high resolution figures, can be found at: http://n.neurology.org/content/83/14/1223.full

Information about reproducing this article in parts (figures,tables) or in its entirety can be found online at:

http://www.neurology.org/about/about_the_journal\#permissions

Information about ordering reprints can be found online:

http://n.neurology.org/subscribers/advertise

Neurology ${ }^{\circledR}$ is the official journal of the American Academy of Neurology. Published continuously since 1951, it is now a weekly with 48 issues per year. Copyright () 2014 American Academy of Neurology. All rights reserved. Print ISSN: 0028-3878. Online ISSN: 1526-632X.

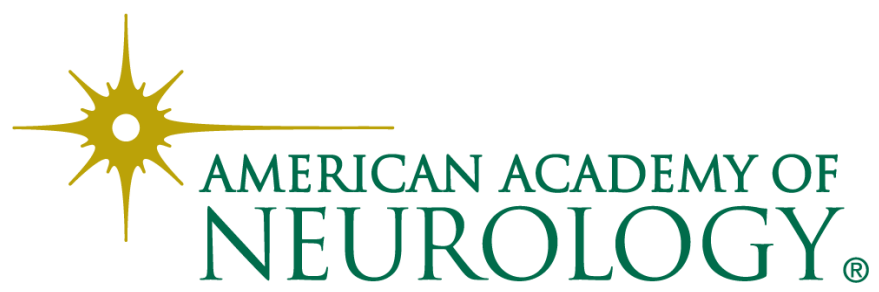

